\title{
Entre a entrega e a renúncia: excelência acadêmica em escolas públicas chilenas de alta performance
}

Maria Luísa Quaresma'

\section{Resumo}

A excelência é um dos conceitos-chave da nova retórica educativa. Este artigo procura refletir sobre as representações sociais de excelência partilhadas por diretores e alunos dos dois últimos anos do ensino médio de duas escolas públicas de alto rendimento localizadas em Santiago do Chile, capital de um dos países do mundo mais permeável às lógicas de mercantilização da educação. Propõe-se ainda a dar conta dos custos que a demanda da excelência envolve, em termos emocionais e de gestão dos tempos de lazer e de sociabilidade. Num primeiro momento, caracterizar-se-á o sistema educativo chileno e discutir-se-á o polissémico conceito de excelência, desde as concepções mais performativas às mais enfocadas nos projetos de formação integral. A abertura do sistema educativo do Chile à privatização, avaliação e accountability deixaria prever uma forte adesão à vertente acadêmica da excelência por parte dos agentes educativos dessas escolas. No entanto, os dados recolhidos através de técnicas intensivas e extensivas (entrevistas individuais com equipes diretivas e estudantes e grupos de discussão e inquéritos por questionário com alunos) revelam percepções matizadas, com os estudantes a integrarem mais vincadamente, na sua representação social de excelência, dimensões não performativistas e utilitaristas. Quanto ao modo como os alunos vivenciam a demanda da excelência, prevalecem os testemunhos de estados de ansiedade e estresse, em alguns casos de elevada gravidade, e os relatos de uma sobrecarga diária com as tarefas acadêmicas, a qual não deixa o necessário espaço para o estabelecimento das redes de sociabilidade e lazer que são parte integrante da identidade juvenil.

\section{Palavras-chave}

I- Universidad Autónoma de Chile, Santiago, Chile.

Excelência - Escola pública - Ofício do aluno.

Contato: quaresma.m|@gmail.com 


\title{
Between engagement and renouncement: academic excellence in high performance state schools
}

Maria Luísa Quaresma'

\begin{abstract}
Excellence is a key-concept of the new educational rhetoric. This paper aims at reflecting on social representations of excellence shared by principals and students attending the last two years of secondary education in two high performance state schools located in Santiago (Chile), the capital of one of the most permeable countries to the commodification of education. It also aims at reflecting on the costs of pursuing excellence, concerning emotional dimension and free time to leisure and sociability. Firstly, we will characterize the Chilean educational system and we will discuss the polysemic concept of excellence, from the most performative definitions to those focused on a holistic perspective of education. Due to the openness of the Chilean educational system to privatization, evaluation and accountability, we would predict that these schools' educational agents would share a strong attachment to the academic dimension of excellence. However, based on data collected through intensive and extensive techniques (individual interviews with school management teams and students and focus groups and surveys with students), we find evidence that students share nuanced perceptions and that they markedly do not include performative and utilitarian dimensions in their social representations of excellence. Concerning the way how students experience the pursuit of excellence, their speeches have revealed anxiety and stress disorders, often very severe, and also a busy daily workload, due to heavy academic tasks that do not allow them the essential free time to establish the networks of sociability and leisure that are part of youth identity.
\end{abstract}

\section{Keywords}

Excellence - State schoos - Student's job.

I- Universidad Autónoma de Chile, Santiago,

Chile.

Contact: quaresma.ml@gmail.com 
A permeabilidade dos sistemas educativos às lógicas de mercado está na ordem do dia. Com maior ou menor intensidade, diferentes países abriram-se aos postulados de uma nova retórica educativa que defende a diminuição do peso do Estado na educação e a adesão das escolas ao modelo empresarial, baseado no critério da qualidade, da eficiência e da competitividade. Este artigo tem por cenário a realidade educativa do Chile, um dos países do mundo que mais se deixou contaminar pelas lógicas neoliberais da performatividade. Baseia-se nos resultados exploratórios de uma pesquisa sobre a excelência levada a cabo em dois prestigiados liceus emblemáticos de Santiago (um masculino e um feminino), ou seja, escolas públicas que aliam excelência, tradição e prestígio.

Quais são as representações sobre a excelência de alunos e diretores? Cingem-na eles à sua dimensão performativa em termos de resultados acadêmicos ou têm dela uma concepção mais holística? Qual é a relação entre essa conceitualização do êxito e as configurações do sistema educativo chileno? Como vivem os alunos as eventuais tensões entre ser jovem e ser aluno de excelência? Eis algumas perguntas para as quais procuraremos respostas.

Num primeiro momento de contextualização da realidade educativa, discutiremos a configuração do sistema educativo chileno no que diz respeito às tendências de privatização de escolas e à transferência e descentralização da administração dos estabelecimentos de ensino do Estado para os municípios, criando um sistema subdividido em três tipos de escolas: municipais, particulares pagas e particulares subvencionadas. Problematizaremos também a adesão aos mecanismos de accountability e aos processos de subsídio estatal às escolas privadas, através do sistema de vouchers. Seguidamente, debateremos, também numa ótica conceptual, o significado de excelência, desde as concepções mais performativistas até as mais multidimensionais, procurando problematizar igualmente os custos dessa demanda.
Depois de sintetizados os procedimentos metodológicos da pesquisa, poremos o enfoque nos resultados obtidos através da análise das entrevistas com diretores e outros responsáveis da equipe de direção, do inquérito por questionário aplicado a uma amostra de 630 jovens do $3^{\circ}$ e $4^{\circ}$ anos do ensino médio, e dos grupos de discussão e entrevistas individuais realizados com estudantes.

Os resultados exploratórios dão conta, desde já, de duas tendências: por um lado, a representação social de excelência mais focalizada nos resultados acadêmicos partilhada pelos diretores, em convergência com as exigências de um sistema escolar de matriz marcadamente gerencialista - mas que já vem sendo posta em causa pela nova direção da escola feminina - e que contrasta com a posição mais matizada dos estudantes, que agregam ao significado de excelência dimensões não ancoradas no paradigma da competição e da performance; por outro lado, o excessivo peso da vida acadêmica na agenda diária desses alunos, que lhes rouba tempo de fruição do presente, confrontando-os com as tensões inerentes à “(...) gestão entre temporalidades de investimento nos estudos em regime 'de alta competição' e temporalidades de investimento nas sociabilidades juvenis em regime de 'alta pressão"” (VIEIRA, 2014, p. 49).

\section{Sistema escolar chileno:} privatização e accountability

A corrente liberal em educação, que nos anos 1980 surgiu com força nos países anglosaxônicos, depressa permeabilizou a agenda educativa de países localizados em continentes tão longínquos e distintos como a Ásia ou a América do Sul (VAN ZANTEN, 2000). 0 Chile figura entre os países do mundo que, no campo da educação, mais se deixou contaminar pelas lógicas neoliberais e pela "nova cultura de performatividade competitiva” (BALL, 2002, p. 8) que as caracteriza, norteando a sua política educativa por três dos princípios nucleares da 
ideologia do mercado educacional: a escolha da escola, a concorrência entre estabelecimentos de ensino e a privatização da educação (CHUBB; MOE, 1990; HOWELL; PETERSON, 2006). A ditadura de Pinochet marca o início do processo de transformação do país no "caso mais radical de sistema escolar nacional regulado por mecanismos de mercado" (COX, 2012, p. 14), datando dos anos 1980 a substituição da narrativa educacional centro-estatista pela narrativa de mercado ou competitiva (CORVALÁN, 2013). Com um sistema de educação misto, o Chile tem três tipos de escola - escolas municipais, escolas particulares subvencionadas e escolas particulares pagas -, as duas primeiras concentrando em 2010 mais de 90\% da população estudantil chilena (MIZALA; TORCHE, 2012), uma vez que, segundo os mesmos autores, as escolas particulares pagas, dependentes exclusivamente das mensalidades das famílias, permanecem inacessíveis à maioria dos jovens chilenos, sendo frequentadas pelas classes socioeconômicas mais favorecidas.

Um dos passos intermédios da transição para o sistema de mercado educacional correspondeu ao processo de municipalização das escolas públicas. Considerado a "meio caminho entre uma educação pública e privada" (CORVALÁN, 2013, p. 63-81), o processo de municipalização introduzirá a segmentação e segregação na própria rede estatal, já que passará a haver escolas públicas com melhores ou piores condições em função dos maiores ou menores recursos financeiros, técnicos e de gestão do município que as gere (BUDNIK et al., 2011).

As escolas municipalizadas irão registrar perdas significativas de alunos que são acompanhadas do aumento expressivo de matrículas nas escolas privadas (BELLEI; GONZÁLEZ; VALENZUELA, 2010), no quadro de uma política de forte incremento à privatização do ensino que lança a educação pública chilena numa "crise de enorme magnitude" (p. 233). Implementada em nível nacional e apoiada no recurso ao voucher (CARNOY; MCWEAN, 2000) - um dos fatores responsáveis pela estratificação escolar (PORTALES; VASQUEZ, 2012) - essa política transformou o Chile num dos países da Organização para a Cooperação e Desenvolvimento Econômico (OCDE) com maior participação do setor privado na educação (OCDE, 2012). Parte dele passou mesmo a ser financiado por recursos públicos, dando origem à figura das "escolas particulares subvencionadas”, em forte expansão desde os anos 1980. Transformado num "verdadeiro apartheid educativo" (BUDNIK et al., 2011, p. 314), o sistema escolar chileno integra escolas municipais que concentram elevado número de jovens vulneráveis (COX, 2012) e sofrem a descremação dos seus melhores alunos (ALLENDE; VALENZUELA, 2012), confrontando-se com a inevitabilidade da "espiral de declínio" (DURU-BELLAT; MEURET, 2001, p. 214) e escolas privadas com voucher que não só evitam os jovens socialmente desfavorecidos (BELLEI, 2009) como selecionam os alunos de maior potencial acadêmico (HSIECH; URQUIOLA, 2006), nomeadamente através do recurso a exames de entrada e outros mecanismos de seleção de uso muito frequente no setor privado subvencionado (CONTRERAS; SEPÚLVEDA; BUSTOS, 2010).

Em linha com os princípios neoliberais da avaliação e da accountability (AFONSO, 2012), o sistema educativo chileno implementou provas estandardizadas de avaliação dos alunos, como é o caso do Sistema de Medición de la Calidad en Educación (SIMCE) e da Prueba de Selección Universitaria (PSU), e consolidou uma estrutura de controle e análise dos estabelecimentos de ensino, de que fazem parte a Agencia de Calidad e a Superintendencia de Educación. As preocupações educativas com a promoção da qualidade, da excelência e do mérito (TORRES, 2014) vão levar à criação, em 2011, dos Liceos Bicentenários, estabelecimentos maioritariamente públicos que pretenderam ser uma réplica dos tradicionais e prestigiados Liceos Públicos de Excelência (LPE), entre os quais se contam os dois estabelecimentos de ensino onde decorre esta pesquisa. Criados num período 
em que a educação era ainda um feudo das elites chilenas, os LPE viriam a expandir-se ao longo das décadas 1930 1940, afırmando-se no cenário escolar como escolas públicas de elevada exigência acadêmica, onde jovens socialmente vulneráveis mas de elevado empenho e potencial acadêmico encontrariam o locus educativo ideal para ascenderem social e escolarmente. Uma aura que mantêm até hoje, em grande parte alicerçada nos bons resultados dos seus alunos na prova SIMCE, mas que suscita reserva a pesquisadores que denunciam a percentagem residual de alunos socialmente vulneráveis que os frequentam e põem em causa o valor acrescentado das suas estratégias para o seu melhor desempenho acadêmico, que eles explicam pela seleção e descremação dos melhores alunos (ALLENDE; VALENZUELA, 2012).

\section{Problematizando o conceito de excelência no campo educativo}

Os valores da excelência e da meritocracia têm vindo, de fato, a ganhar uma relevância crescente no campo escolar. A multiplicação, no espaço escolar português, de diferentes mecanismos de distinção - quadros de honra, concursos, louvores, bolsas de mérito - que premeiam e estimulam os melhores alunos (TORRES, 2014) ou o lançamento na França, a partir de 2008, dos Internats d'Excellence são reveladores da inscrição da excelência escolar nas respectivas prioridades nacionais e da valorização do mérito. A iniciativa francesa tem como principais destinatários jovens socialmente vulneráveis, mas com potencial acadêmico e motivação, que, não tendo no contexto familiar condições favoráveis ao desenvolvimento das suas potencialidades e à concretização de um percurso escolar de êxito, encontrariam nos Internats d'Excellence as condições que lhes permitiriam alcançar a excelência a que aspiram (RAYOU; GLASMAN, 2012).

A permeabilidade do campo escolar à lógica empresarial, a imagem de uma escola em crise (QUARESMA, 2014a), mas também a perda da hegemonia da nova classe média (BERNSTEIN, 2001) nos sistemas educativos, fruto da massificação escolar, da inflação de diplomas e da consequente necessidade de encontrar um novo sinal de distinção que lhes permita assegurar vantagens posicionais aos filhos (BROWN, 2003), alimentam a cruzada a favor da demanda da excelência (MAGALHÃES; STOER, 2002; CORTESÃO et al., 2007) que agora atravessa todo o sistema educativo, do setor público ao privado. Ela constituirá, aliás, um dos elementos identitários das classes dominantes (PINÇON; PINÇON-CHARLOT, 2007), educadas em prestigiadas escolas (ALMEIDA; NOGUEIRA, 2003; BRANDÃO; LELLIS, 2003; ALMEIDA, 2009), onde a concepção de excelência, no entanto, extravasa a mera performance acadêmica (QUARESMA, 2014b), revestindo-se de uma pluridimensionalidade que constitui, afınal, a marca de distinção da educação burguesa destinada à preparação de uma elite intelectual e moral que se considera destinada a grandes missões (PINÇON; PINÇON-CHARLOT, 2007).

0 conceito de excelência escolar "aparece sempre na Sociologia como uma questão sensível, e sujeita a inúmeras interrogações" (RESENDE, 2014, p. 75). Uma das mais prementes, em democracia, gira em torno da tensão entre mais ou melhor escola, ou seja, do dilema entre alargar as oportunidades educativas a um maior número de alunos, aceitando a inevitabilidade do abaixamento de nível das aprendizagens, ou educar um pequeno número de alunos segundo padrões de elevada qualidade (BROWN; KURZWEIL; TOBIN, 2005). Mingat e Duru-Bellat (2011), que se interrogam, por exemplo, sobre a possibilidade de ser considerado excelente um sistema de ensino que produz fortes desigualdades performativas entre os seus alunos, falam de um conceito complexo e de difícil defınição e avaliação, lembrando que ele tanto pode remeter para a longevidade da trajetória escolar ou para a qualidade dos resultados, para o percurso escolar enquanto 
aluno ou para a integração social e profissional enquanto adulto, para o domínio cognitivo e/ou para o domínio dos valores e comportamentos.

A questão do "ser excelente em quê?" é, aliás, muito pertinente, dada a heterogeneidade de motivações, competências e áreas de interesse dos alunos que a escola deverá não só estimular mas também considerar como objeto de avaliação de excelência, como dizem Van Avermaet, Van Houtte e Van Branden (2011), defensores de que, a par do reconhecimento da excelência num núcleo central de conhecimentos comuns a todos os alunos, o sistema escolar reconheça essa "excelência diferencial" (p. 9) que cada aluno pode desenvolver em função dos seus próprios talentos. Cortesão et al. (2007), por sua vez, destacam o caráter polissêmico e ambíguo do conceito de excelência acadêmica, apoiados nas diferentes representações institucionais que encontraram no quadro dos estudos de caso desenvolvidos em quatro reputadas escolas portuguesas. Tendo como instrumento de análise um "continuum em cujos extremos se localizaria pedagogia e performance" (p. 19) constataram, a partir da análise discursiva de professores, pais e alunos das diferentes escolas, que o seu conceito de excelência acadêmica assume contornos matizados, em que se mesclam preocupações pedagógicas por parte dos performativistas e preocupações com a performance por parte dos pedagogistas. Perrenoud (1984), por sua vez, vem lembrar que a definição das formas de excelência e das normas que a regem varia segundo os sistemas educativos, as épocas, os níveis e mesmo as vias de ensino, problematizando a questão da fabricação da excelência escolar. Indissociável da ideologia do mérito - essa ficção reconfortante para o indivíduo e necessária para a sociedade que se internaliza no espaço escolar (DURUBELLAT; TENRET, 2009) -, a excelência não é mais do que uma realidade construída pela escola, segundo aquele pesquisador. Ela é a detentora do poder de definir as normas a partir das quais, e sob a mediação do professor, os alunos serão ou não avaliados como excelentes, num processo que envolve inevitavelmente a criação de hierarquias de excelência, assentes na maior ou menor distância relativamente à norma padrão arbitrariamente determinada, mas internalizada como natural. A apreciação da excelência, ausente da "semântica de avaliação" (RESENDE, 2014, p.84) nos cursos profissionalizantes, contemplará, no ensino regular, duas dimensões distintas mas complementares: um bom trabalho na aula e fora dela, com tradução nas "boas provas” (RESENDE, 2014, p. 85), mas também um bom comportamento, traduzido em assiduidade, em pontualidade e em responsabilidade. Quanto às "gramáticas de motivos" (RESENDE, 2014, p. 76) que mobilizam os alunos para a excelência escolar, delas farão parte os esperados elogios da família, o apreço dos professores, ou a admiração dos colegas (PERRENOUD, 1995), gratificações não isentas de custos (PERRENOUD, 1995; FERRARI, 2002; BROWN, 2013), como o da alunização das suas vidas (CORREIA; MATOS, 2001), da secundarização da dimensão central da condição juvenil, que é a sociabilidade (DAYRELL, 2007), de tensões com colegas que os identificam, depreciativamente, com a tipologia dos "marrões"1 (DUBET; MARTUCCELLI, 1996). 0 estresse e a angústia provocados pelo receio de defraudar as auto e hetero-expectativas (VIEIRA, 2014) podem mesmo levar à "neurose da excelência" (AUBERT, 1993, p. 87), característica das situações de trabalho em que "o indivíduo é conduzido a desenvolver e buscar uma imagem de si mesmo em conformidade com os padrões exteriores de excelência e de sucesso, às vezes, em detrimento de sua personalidade real" (p. 102).

\section{Considerações metodológicas}

Os resultados apresentados resultam de uma pesquisa exploratória intitulada $L a$ escuela pública y la fabricación de la excelencia académica: representaciones sociales $\mathrm{y}$ prácticas estudiantiles y organizacionales, que se encontra em execução e que é financiada pela Universidad Autónoma de Chile. Esse

\section{1- 0 termo marrão é utilizado para se referir a aluno muito estudioso.}


estudo está sendo desenvolvido nos dois mais prestigiados liceus emblemáticos de Santiago do Chile - um masculino e outro feminino e tem por objetivo analisar as representações sociais sobre a excelência partilhadas pelas equipes diretivas e por estudantes dos dois últimos anos do ensino médio, bem como as estratégias de alunos e escolas para alcançá-la. Neste artigo, incidiremos a nossa análise sobre as concepções de excelência partilhadas pelos agentes educativos e sobre a conciliação entre tempos de estudo e de juventude.

Os estabelecimentos de ensino escolhidos para este estudo recebem alunos desde o $7^{\circ}$ básico até ao $4^{\circ}$ médio ${ }^{2}$ e aliam à excelência dos seus resultados acadêmicos nas provas nacionais uma longa tradição como escolas de prestígio e um amplo reconhecimento público. A escola masculina foi criada em 1813, ainda quando o Chile estava sob a dependência da monarquia espanhola, e tem como lema Labor omnia vincit (o trabalho tudo vence) e como principal missão "dar à pátria cidadãos que a defendam, dirijam e façam florescer e lhe deem honra”. Mais recente, mas já elevada à categoria de liceu emblemático, a escola feminina abriu as portas em 1961. Ambas são de frequência gratuita e totalmente financiadas pelos respetivos municípios. Dado que, ano após ano, a procura supera a oferta de vagas, essas escolas procedem à seleção dos alunos que agora, terminado o filtro dos requisitos mínimos para a candidatura, é feita apenas através de um exame cujas notas determinam o ingresso dos candidatos.

Os dados apresentados neste artigo resultam da aplicação de um conjunto de técnicas de pesquisa ancoradas tanto no paradigma quantitativo como qualitativo: entrevistas exploratórias em profundidade com diretores, inspetores gerais ${ }^{3}$ e chefes das

2 - 0 sistema escolar chileno divide-se em ensino básico $\left(1^{\circ}\right.$ ao $8^{\circ}$ básico $)$ e ensino médio ( $1^{\circ}$ ao $8^{\circ}$ médio).

3- Os inspetores gerais integram a direção das escolas e têm por função garantir o funcionamento das atividades letivas e não letivas nomeadamente assegurando o controle da disciplina e pontualidade dos unidades técnico-pedagógicas ${ }^{4}$, inquérito por questionário aplicado a uma amostra de 630 alunos selecionados aleatoriamente, e nove entrevistas individuais e grupos de discussão realizados com estudantes (total: sete alunas e onze alunos). Ainda que, num primeiro momento, se tenha privilegiado a realização de grupos de discussão compostos por três a cinco alunos com o intuito de maximizar as potencialidades do debate sobre o tema da excelência, o curso da pesquisa obrigou-nos a recorrer às entrevistas individuais nos casos em que os estudantes assim o solicitavam, argumentando, na maioria das vezes, sentiremse desconfortáveis ao ter de partilhar as suas vivências com os demais colegas.

A maioria dos alunos dessas escolas não tem o perfil de herdeiro bourdieusiano, contrariamente ao que acontece nas escolas de excelência (ALMEIDA, 2009). De fato, se 47\% das mães dos alunos têm um curso superior, uma percentagem idêntica concluiu apenas o ensino médio $(45,6 \%)$ - valores que, entre os pais atingem $40,1 \%$ e $51,1 \%$, respectivamente. Apenas 0,6\% dos pais desses alunos e nenhuma das mães integram a categoria de proprietário, diretor ou alto executivo de grandes empresas. $\mathrm{Na}$ sua maioria, os pais e mães trabalham como dependentes no setor privado (45\% e $29 \%$ ) e público (14\% e 15\%). As principais funções profissionais dos pais e mães são "empregado administrativo de empresa privada ou pública" (25,7\% e $24,3 \%)$, "profissionais de carreiras técnicas ou paramédicas, trabalhando em forma dependente" $(15,8 \%$ e 16,9\%) e "profissionais com graduação trabalhando de forma dependente" (14,6\% e 12,4\%). Expressiva é ainda a percentagem de progenitores "operários, capatazes ou microempresários" (9,1\% no caso dos pais e 17,7\% no das mães). Estando a cidade de Santiago estruturada em

alunos, verificando o cumprimento dos horários dos professores, dos livros de assistência etc.

4- Os chefes das unidades técnico-pedagógicas têm a seu cargo principalmente assessorar os docentes, coordenar, supervisionar e avaliar as atividades curriculares, assistir a aulas e cursos para promover a eficiência dos docentes e garantir o cumprimento dos programas escolares. 
bairros social e economicamente heterogêneos, importa referir que os alunos vivem, na sua maioria, em "comunas" onde estão ausentes as franjas sociais mais capitalizadas, como é o caso de Maipú (15\%), Santiago Centro, La Florida e Puente Alto (cada uma delas com 8\%, aproximadamente) e Pudahuel (6\%).

Em consonância com 0 estatuto sociocultural das suas famílias, a maioria dos alunos inquiridos provém de colégios particulares-subvencionados (68\%) e de escolas municipais (22\%), sendo poucos os que frequentaram escolas particulares pagas (10\%). As suas expectativas de carreira acadêmica são muito homogêneas. Apenas uma percentagem residual $(0,5 \%)$ declarou querer terminar a sua trajetória acadêmica no fim do ensino médio e mais de 60\% tem como intenção concluir um doutorado ou pós-doutorado.

\section{Percepções sobre a excelência:}

entre a formação acadêmica e a formação integral

Como demos conta na incursão teórica, o sistema educativo chileno não ficou imune às lógicas de competitividade inerentes a um modelo educativo de mercado. Poder-se-ia, assim, prever que os agentes entrevistados nesses liceus emblemáticos tivessem interiorizado um conceito de excelência marcado pela performatividade que caracteriza o atual paradigma educativo. De fato, e ainda que o projeto educativo da escola masculina identifique como objetivo a formação integral dos seus alunos, é a dimensão cognitiva que atravessa o discurso do seu diretor, quando solicitado a defınir a excelência. Ela passa, nas suas palavras, "por definir um conjunto de etapas ou passos para alcançar a meta ou objetivo que uma escola se propõe" e que, no caso desses estabelecimentos, traduz-se na obtenção da maior pontuação possível nas provas nacionais e nos exames de acesso ao ensino superior, como nos dirá depois, lembrando que desses resultados depende o acesso à universidade e ao curso de primeira opção dos alunos e a preservação da imagem pública de qualidade dos colégios. A excelência é, pois, lida “desde um ponto de vista numérico ou acadêmico (...) desde uma forma externa, através das provas PSU, SIMCE... nas quais o colégio tem mantido excelentes posições e pontuações em nível nacional" (inspetor geral, escola masculina), refletindo a cultura de performatividade competitiva que tem como meta central a busca do desempenho máximo dos sujeitos individuais e das organizações, tido simultaneamente como medida de rendimento, prova de qualidade e estratégia de promoção (BALL, 2002).

Ainda que também focalizada nos resultados do SIMCE e da PSU, a diretora da escola feminina não descura outras dimensões da excelência, como a estabilidade emocional das alunas, expressas num discurso em que se mesclam preocupações performativistas e pedagogistas (CORTESÃO et al., 2007) e em que sobressai a sua visão da escola enquanto formadora de "homens completos, mais do que especialistas” (TEDESCO, 2008, p. 60). Na secundarização dessas outras vertentes, como também é o caso das "emoções inerentes ao processo de ensino aprendizagem”, a diretora vê uma "debilidade" do projeto educativo da sua escola, contra a qual diz ter encetado uma luta desde que, recentemente, assumiu a direção do colégio, procurando a conciliação das estratégias enfocadas nos resultados com as direcionadas para a "formação em valores, a formação central da pessoa inteira” (inspetora geral, escola feminina). A necessidade de alargar o sentido de excelência é, de fato, vista como "um impulso da nova diretora”, como dirá essa inspetora, numa alusão ao papel da liderança na escola e da margem de ação do diretor para defınir o "rumo" a seguir, em consonância com a sua visão da educação e do que considera ser o interesse dos seus alunos (PAR0, 2010).

A representação social de excelência dos alunos aproxima-se desta concetualização mais integral do que é ser excelente, sendo 
de registar que as respostas ao inquérito que obtêm maiores percentagens apontam para dimensões extra-acadêmicas da excelência ou para a vertente expressiva da aprendizagem. É assim que a excelência é identificada por 92\% dos inquiridos com a capacidade crítica e reflexiva e por $82,7 \%$ com a igualdade de oportunidades do sistema educativo, em convergência com a problematização da excelência/equidade desenvolvida por Mingat e Duru-Bellat (2011) e com o perfil de alunos que, como os desses colégios, têm protagonizado, até com a "ocupação" dos colégios, a luta em prol de uma educação pública, gratuita e de qualidade iniciada em 2006 pela Primeira Revolução Pinguina (BUDNIK et al., 2011). 0 “aprender por prazer" é assinalado por 83\% dos inquiridos que, talvez por estarem já seguros da boa formação instrutiva assegurada por essas escolas e por sentirem a tranquilidade de quem já tem essa vantagem competitiva no mercado escolar, ficarão com "margem" para aspirar a outras dimensões do êxito. São as meninas que mais valorizam o "aprender por prazer" seja por efeito da impregnação pela cultura de descentramento dos resultados acadêmicos imprimida pela atual diretora do colégio feminino, seja por efeito de uma socialização de gênero que tende ainda a educar as meninas nos valores da expressividade (AMÂNCIO, 1994) e que se pode acentuar em escolas com educação não mista, como é o caso desta. Digno de registo é o fato de uma larga maioria dos alunos $(73,5 \%)$ rejeitar a premissa de que ser excelente é ser o melhor aluno da turma, numa demarcação do binômio competição com a alteridade / excelência que está subjacente à retórica educativa neoliberal e aos seus dispositivos de avaliação e accountability, como os testes estandardizados e os rankings das escolas (AFONSO, 2012).

5- Todas as correlações entre variáveis são significativas em níveis de 95\% ou 99\% de confiança. Para as correlações entre variáveis nominais/ ordinais, utilizou-se o teste do . No caso das análises que incluem variáveis de escala, utilizou-se 0 teste T.
A excelência surge antes associada com a competição consigo mesmo, como se depreende pelas entrevistas dos alunos, para quem ela é identificada com a capacidade de atingir objetivos, de se autossuperarem e, como é reafirmado por 95,5\% dos inquiridos, com a capacidade de se "esforçarem continuamente". 0 esforço, também enfatizado como dimensão da excelência no estudo de Brown (2013), é, aliás, central no discurso meritocrático e de responsabilidade individual que, no caso concreto da meritocracia escolar, potencia a autoculpabilização dos excluídos das fileiras da excelência pelo seu insucesso (TORRES, 2014). Figurando como ideal de conduta nos projetos educativos desses colégios, o sentido de esforço remete, afinal, para o duro e continuado trabalho sobre si mesmo que a busca da excelência envolve para a grande maioria dos alunos (PERRENOUD, 1995). Como nos diz uma aluna entrevistada, a excelência é "partir das expectativas que construímos ao longo da vida (...) a primeira coisa que me vem à cabeça quando falo disso, mais do que o monetário ou coisas assim, é sentir-me plena, cumprindo uma meta”.

A desvalorização discursiva da vertente mais utilitarista da excelência (patente também nas percentagens de 25,4\% e 38,9\% de inquiridos que a associam a carreiras de prestígio e ao ingresso nas melhores universidades) não implica, no entanto, a rejeição da vertente acadêmica da excelência e da sua condição de alunos pertencentes a uma "elite escolar". Para eles, ser excelente passa por "aprender os conhecimentos científıcos ensinados na escola”, como disseram $71,5 \%$, e é também sinônimo de frequentar esses colégios, o que, tendo em conta a seletiva barreira de ingresso, significa ter sido "posto à prova" - e a excelência tem de ser pensada à luz da sociedade de provas e de testes (RESENDE, 2014) - e tê-la superado com êxito. Porque “(...) a seleção é também 'eleição' (...)”, como afırma Bourdieu (1989, p. 40) e como nos diz também uma das alunas: "quando há seleção, só alguns são escolhidos e então uma pessoa sente 'Oh... Fiquei!”. É notório o sentimento de orgulho de 
pertença à instituição que atravessa os discursos de todos os alunos entrevistados, a exemplo do verificado nos colégios privados de elite (QUARESMA, 2014a). Mas, no caso dos jovens destas duas escolas chilenas, porque gratuitas, o orgulho é tanto mais acentuado quanto radica na percepção de que o seu ingresso nelas se deve apenas ao seu mérito escolar e não ao poder econômico ou às redes de influência da família.

No entanto, implicando a agregação ao escol de eleitos a separação do grupo de excluídos que é vivenciada com alguma culpabilidade por parte dos "trânsfugas" (BOURDIEU, 1989) e tendo estas escolas alunos em processo de mobilidade social ascendente, não surpreende que muitos dos alunos entrevistados vivenciem este sentimento de orgulho com uma mescla de incômodo, dizendo que, nas interações estabelecidas com os pares de outras escolas, sentem-se constrangidos e com medo de parecerem "vaidosos por ser do Instituto", como nos refere um aluno da escola masculina - uma vaidade reforçada pela consciência de que a frequência desses colégios funciona como um passaporte para um futuro promissor: "Destes colégios, têm saído muitos presidentes, gente importante. Então, quando uma pessoa diz que é do Instituto, logo as pessoas pensam numa espécie de triunfo (...) sabem que a pessoa que está no Instituto vai triunfar na vida; como dizem as pessoas: estudar aqui é o único meio para entrar na universidade". 0 hino do colégio glorifica, aliás, essa imagem de escola formadora de líderes, exaltando e incentivando as "conquistas institutanas": "Digamos o que fomos, em épocas distantes, os homens que hão surgido do nosso imenso lar; olhando para o passado de exemplo edificante, saberemos outros cumes mais altos escalar".

\section{Os custos da excelência:}

frustração, renúncia e resignação

Esse "escalar a montanha" do êxito escolar, a crer nos dados do inquérito, estará longe de ser uma via sacra de renúncias e de sacrifícios, onde se incluem a abdicação dos tempos de lazer e crises de estresse e angústia (PERRENOUD, 1995). Talvez numa demarcação do perfil depreciativo de alunos "marrões" (DUBET; MARTUCCELI, 1996), a quase totalidade dos inquiridos discorda que a excelência implique "não conviver com os amigos" (93\%), "não fazer mais nada que estudar" (93\%), "renunciar às atividades de ócio" (91\%), "viver angustiado e estressado" (89\%) e "estudar muitas horas" (82\%). Ainda que, em geral, as médias dos alunos não sejam muito díspares, são os alunos com notas um pouco mais baixas (médias de 5.8 e 5.7, respetivamente ${ }^{6}$ ) que mais tendem a concordar com estas últimas afırmações. Estando imersos numa cultura escolar de competitividade, como é reconhecido por 90\% dos inquiridos e como dão conta as entrevistas realizadas, não surpreende que os alunos com piores médias estejam mais expostos a estados de angústia e estresse do que os colegas com maior sucesso e, logo, tenham de se empenhar mais no ofício de aluno, dedicando um maior número de horas às atividades escolares.

A interação de proximidade propiciada pelas entrevistas vai abrir a porta a confidências que, fluindo timidamente, vão permitir esbater a assertividade das respostas ao inquérito no que toca aos custos da demanda da excelência. 0 recurso à palavra sobreviver, usada por diferentes alunos quando falam do seu quotidiano na escola é, a esse título, elucidativo, não diferindo da percepção de vivência escolar encontrada noutras escolas de excelência (LACERDA, 2006). Há mesmo quem admita momentos de angústia e de frustração, particularmente intensos durante o primeiro ano no colégio, altura em que os alunos são confrontados com os elevados níveis de exigência acadêmica da nova escola (VIANA, 2011) e despertam para a realidade de que um aluno excelente numa escola mediana pode não conseguir passar de um aluno mediano numa escola excelente (BROWN, 2013). Como

\footnotetext{
6- A escala de notas no Chile varia entre 1 e 7.
} 
nos conta uma aluna, "Cheguei e a minha primeira nota, lembro-me de que a minha primeira nota foi de matemática... entregaramme a prova e tirei 4.9. Nunca na minha vida tinha tido um 4 nem um 5 e aí frustrei-me". Face a um resultado acadêmico aquém da meta de excelência, intensificam-se nalguns alunos os receios de que aquele seja o primeiro de uma longa cadeia de insucessos que comprometa irremediavelmente o projetado futuro acadêmico de excelência e que defraude as auto e as heteroexpectativas (VIEIRA, 2014), paulatinamente alimentadas. Como nos diz um aluno, o pensamento é logo "Ai... assim não vou chegar a lugar algum porque as coisas não me estão a ir bem”. A ansiedade e a angústia agudizam-se num quadro de imersão em culturas de excelência escolar que têm o fracasso como um anátema e que promovem a difusão e internalização de lemas informais como "Errar é humano, mas não institutano", recordado por um dos jovens do Instituto masculino. No caso de alunos de famílias socialmente vulneráveis, a angústia perante o fracasso será ainda acrescida: a entrada de um filho nesses colégios é a sonhada via de acesso para a mobilidade social, como nos explica o diretor do colégio masculino, que nos dá conta de como essas famílias tudo fazem para dar ao filho que conseguiu o inimaginável acesso a essas escolas de elite as melhores condições de espaço e de tranquilidade para estudar em casa, nomeadamente reservando-lhes "um espaço, um retângulo que é sagrado".

Os casos de alunos com depressão serão frequentes, ainda segundo o diretor da escola masculina, que este ano identifica mais de três dezenas. As situações mais graves ocorridas sobretudo no final do ano letivo - têm acompanhamento das escolas, que assumem a responsabilidade de garantir apoio psicológico aos estudantes. Ainda que reconhecendo que "mais fácil seria dizer aos pais: leve o seu filho a uma escola que seja menos exigente" (diretor, escola masculina), os diretores dessas escolas dizem promover também uma reflexão interna
- juntamente com os professores - sobre as causas dessas situações de estresse que, por vezes, chegam à tentativa de acabar com a vida. Como nos conta o diretor da mesma escola, "no ano passado, houve seis tentativas de suicídio no nosso colégio, das quais uma se consumou. Um rapaz suicidou-se. Estamos quase todos com depressão endógena, mas estamos analisando em profundidade o que se está passando, porque talvez o excesso de exigência acadêmica..." conclui, remetendo para o clima de "esquizofrenia estrutural e individual" (BALL, 2002, p. 15) em que a exigência da performatividade e da competitividade terá mergulhado as escolas e os seus agentes.

Ainda que os alunos digam conciliar, sem tensões, os tempos de jovem e de estudante, os relatos do seu quotidiano apontam no sentido de "dias preenchidos" por atividades acadêmicas a que se acrescenta o tempo de deslocação entre a casa e a escola, que, muitas vezes, chega a quatro horas diárias: "De segunda a quinta, é até às 20:30h. Chego às 21:30h, 22h à minha casa e então tenho que estudar para o PreU ${ }^{7}$. Sexta e sábado não vou ao PreU, mas tenho que estudar para a escola. Podia meter-me em alguma atividade, mas já seria muito. Prefiro dormir" (aluna, escola feminina). 0 ritmo de trabalho escolar com que se confrontam leva uma das alunas entrevistadas a admitir que são "alunos máquinas”. Uma outra colega acrescenta: “eu tenho tempo [para estar com os amigos] (...) Mas não estou com eles todas as semanas, senão... Consigo estar com a minha família, o meu namorado e um amigo ou outro...”.

Tendo-se candidatado a escolas que sabiam ser de elevada exigência acadêmica, os alunos de ambos os estabelecimentos se mostram conformados com o pouco tempo que o exigente "ofício de aluno" lhes deixa para estar com os amigos ou para participar de atividades de lazer, sobrevivendo entre a entrega e a renúncia próprias de quem internalizou que o futuro de amanhã se prepara hoje.

7- Aulas de preparação para a PSU. 


\section{Notas conclusivas}

O sistema educativo chileno é um dos mais que se abriu à narrativa de mercado (CORVÁLAN, 2013; COX, 2012) e aos valores da performatividade e da prestação de contas (BALL, 2002), medidas através dos resultados de provas estandardizadas. As escolas analisadas neste artigo são precisamente duas das escolas públicas que lideram os rankings de avaliação de resultados ao longo dos últimos anos e que, além disso, gozam de reconhecimento como liceus emblemáticos.

Estando diretores e alunos desses colégios imersos, desde um ponto de vista macrossocial, num contexto social marcado pelas lógicas de mercado e, desde um ponto mesossocial, em instituições de prestígio e com longa tradição de excelência, onde as pressões para os resultados e para a competitividade são fortes, seria de esperar uma concepção de excelência restrita ao pilar instrutivo avaliado pelos bons desempenhos acadêmicos nas provas estandardizadas. Se é um fato que a representação de excelência dos responsáveis diretivos inclui a dimensão cognitiva, omnipresente no caso do diretor da escola masculina, não é menos verdade que a diretora da escola feminina dá sinais de abertura a uma concepção mais ampla e mais consentânea com a formação de "homens completos" (TEDESCO, 2008), que estará em implementação desde a sua chegada à escola.
No que diz respeito aos alunos, sobressai a sua demarcação da excelência enquanto performance acadêmica, privilegiando a sua concetualização enquanto capacidade crítica e reflexiva (plano individual) e enquanto promoção de equidade do sistema escolar (plano societal), percepções que, como analisamos, também deverão ser lidas à luz do envolvimento dos alunos desses colégios nas dinâmicas de luta social pela educação pública gratuita e de qualidade iniciadas em 2006 (BUDNIK et al., 2011). A rejeição massiva de que a excelência exige abdicações e custos, patente nos inquéritos, vai esbaterse durante as entrevistas, em que recolhemos não só testemunhos de quotidianos preenchidos com atividades escolares e sem tempo para a socialização juvenil, mas também relatos de casos de depressão e tentativas de suicídio, lembradas por um dos diretores desses estabelecimentos de ensino - um quadro de vida onde os alunos dizem sobreviver (LACERDA, 2006), conformados à ideia de que é necessário sacrificar o hoje para conquistar o amanhã (VIEIRA, 2014).

Eis os resultados ainda exploratórios de uma pesquisa em que, pela voz dos agentes educativos que de forma mais direta vivenciam a excelência, captamos a pluralidade de sentidos que atribuem a ela e o modo como experienciam os desafios do caminho longo e por vezes árduo que envolve a sua fabricação (PERRENOUD, 1984). 


\section{Referências}

AFONSO, Almerindo Janela. Para uma concetualização alternativa de accountability em educação. Educação e Sociedade, Campinas, v. 33, n. 119, p. 471-484, abr./jun. 2012.

ALLENDE, Claudio; VALENZUELA, Juan Pablo. Logros en liceos públicos de excelencia en Chile: ¿valor agregado o sólo descreme de la elite? In: CONGRESO INTERDISCIPLINARIO DE INVESTIGACIÓN EN EDUCACIÓN - CIIE, 2., Santiago, 2012. La educación em la encucijada: segundo congresso... Santiago: Universidad de Chile, 2012.

ALMEIDA, Ana Maria Fonseca. As escolas dos dirigentes paulistas: ensino médio, vestibular, desigualdade social. Belo Horizonte: Argvmentvm, 2009.

ALMEIDA, Ana Maria Fonseca; NOGUEIRA, Maria Alice (Orgs.). A escolarização das elites: um panorama internacional da pesquisa. Petrópolis: Vozes, 2003.

AMÂNCIO, Lígia. Masculino e feminino: a construção social da diferença. Porto: Afrontamento, 1994.

AUBERT, Nicole. A neurose profissional. Revista de Administração de Empresas, São Paulo, v. 33, n. 1, p. 84-105, jan./fev. 1993.

BALL, Stephen. Reformar escolas, reformar professores e 0 terror da performatividade. Revista Portuguesa de Educação, Braga, v. 15, n. 2, p. 3-23, 2002.

BELLEI, Cristián. The public-private school controversy: the case in Chile. In: CHAKRABARTI, Rajashri; PETERSON, Paul. School choice international, exploring public-private partnerships. Cambridge: The MIT Press, 2009. p. 165-192.

BELLEI, Cristián; GONZÁLEZ, Pablo; VALENZUELA, Juan Pablo. Fortalecer la educación pública: un desafío de interés nacional. In: BELLEI, Cristián; CONTRERAS, Daniel; VALENZUELA, Juan Pablo. (Eds.). Ecos de la Revolución Pingüina: avances, desafíos y silencios de la reforma educacional. Santiago: Pehuén, 2010.

BERNSTEIN, Basil. La estructura del discurso pedagógico: clases, códigos y control. 4. ed. Madrid: Morata, 2001.

BOURDIEU, Pierre. La noblesse d'etat: grandes écoles et esprit de corps. Paris: Les Editions de Minuit, 1989.

BRANDÃO, Zaia; LELLIS, Isabel. Elites acadêmicas e escolarização dos filhos. Educação e Sociedade, Campinas, v. 24, n. 83, p. 509-526, ago. 2003.

BROWN, Kim. Excellent me! Investigating scholastic identities and learning within discourses of excellence. 2013. Dissertação (Mestrado) - College of Education, University of de Otago, New Zeland, 2013.

BROWN, Phillip. The opportunity trap: education and employment in a global economy. European Educational Research Journal, v. 2, n. 1, p. 141-179, 2003.

BROWN, William; KURZWEIL, Martin; TOBIN, Eugene. Equity and excellence in american higher education. Virginia: University of Virginia Press, 2005.

BUDNIK, Jenny et al. La empresa educativa chilena. Educação e Sociedade, Campinas, v. 32, n. 115, p. 305-322, abr./jun. 2011. CARNOY, Martin; McEWAN, Patrick. Competition and sorting in chile's voucher system. Stanford: Stanford University, 2000. Manuscript.

CHUBB, John; MOE, Terry. Politics, markets, and America's schools. Washington, DC: Brookings Institution Press, 1990.

CONTRERAS, Dante; SEPÚLVEDA, Paulina; BUSTOS, Sebastián. When schools are the ones that choose: the effects of screening in Chile. Social Science Quarterly, v. 91, p. 1349-1368, 2010.

CORREIA, José Alberto; MATOS, Manuel. Da crise da escola ao escolocentrismo. In: STOER, Stephen; CORTESÃO, Luíza; CORREIA, José Alberto. Transnacionalização da educação. Porto: Afrontamento, 2001. p. 91-117. 
CORTESÃO, Luiza (Coord.). Na girândola de significados: polissemia de excelências em escolas portuguesas do século XXI. Porto: Legis, 2007.

CORVALÁN, Javier. La narrativa educacional chilena y su proceso de transformación reciente: un análisis sociológico-histórico. Folios, Bogotá, n. 37, p. 63-81, jan./jun. 2013.

COX, Cristián. Política y políticas educacionales en Chile 1990-2010. Revista Uruguaya de Ciencia Política, Montevideo, v. 21, n. 1, p. 13-41, jan./jun. 2012.

DAYRELL, Juarez. A escola «faz» as juventudes? Reflexões em torno da socialização juvenil. Educação e Sociedade, Campinas, v. 28, n. 100, p. 1105-1128, out. 2007.

DUBET, François; MARTUCCELLI, Danilo. À l'école: sociologie de l'expérience scolaire. Paris: Seuil, 1996.

DURU-BELLAT, Marie; MEURET, Denis. Nouvelles formes de régulation dans les systèmes éducatifs étrangers: autonomie et choix des établissements scolaires. Revue Française de Pédagogie, Lyon, n. 135, p. 173-221, avr.//jui. 2001.

DURU-BELLAT, Marie; TENRET, Elise. L'emprise de la méritocratie scolaire: quelle légitimité? Revue Française de Sociologie, v. 50, n. 2, p. 229-258. 2009.

FERRARI, Michel. Conclusion: what is excellence and how to study it? In: FERRARI, Michel (Org.). The pursuit of excellence through education. New Jersey: Lawrence Erlbaum Associates, 2002. p. 221-240.

HOWELL, William; PETERSON, Paul. The education gap: vouchers and urban schools. Washington, DC: Brookings Institution Press, 2006.

HSIECH, Chang-Tai; URQUIOLA, Miguel. When schools compete how do they compete? An assessment of chile's nationwide school voucher program. Journal of Public Economics, v. 90, p. 1477-1503, 2006.

LACERDA, Wânia Maria G. Famílias e filhos na construção de trajetórias escolares pouco prováveis: 0 caso dos Iteanos. 2006. Tese (Doutorado) - Faculdade de Educação, Universidade Federal Fluminense, Niterói, 2006.

MAGALHÃES, António M.; STOER, Stephen R. A escola para todos e a excelência académica. Porto: Profedições, 2002.

MINGAT, Alain; DURU-BELLAT, Marie. Measuring excellence and equity in education, conceptual and methodological issues. In: VAN DEN BRANDEN, Kris, VAN AVERMAET, Piet; VAN HOUTTE, Mieke (Orgs.). Equity and excellence in education: towards maximal learning opportunities for all students. New York: Routledge, 2011.

MIZALA, Alejandra; TORCHE, Florencia. Bringing the schools back in: the stratification of educational achievement in the Chilean voucher system. International Journal of Educational Development, v. 32, p. 132-144, 2012.

OCDE - Organisation for Economic Co-operation and Development. Public and private schools: how management and funding relate to their socio-economic profile. Paris: OECD, 2012.

PARO, Vitor Henrique. A educação, a política e a administração: reflexões sobre a prática do diretor de escola. Educação e Pesquisa, São Paulo, v. 36, n. 3, p. 763-778, set./dez. 2010.

PERRENOUD, Philippe. La fabrication de l'excellence scolaire: du curriculum aux pratiques d'évaluation. Vers une analyse de la réussite, de l'échec et des inégalités comme réalités construites par le système scolaire. Genebra: Librairie Droz, 1984.

PERRENOUD, Philippe. Ofício de aluno e sentido do trabalho escolar. Porto: Porto Editora, 1995.

PINÇON, Michel ; PINÇON-CHARLOT, Monique. Sociologie de la bourgeoisie. 3. ed. Paris: La Découverte, 2007.

PORTALES, Jaime; VASQUEZ, Julian. Do vouchers create more inequality? Lessons from universal implementation in Chile. Texas: Austin: The University of Texas at Austin, 2012.

QUARESMA, Maria Luísa. Entre o herdado, o vivido e o projetado: estudo de caso sobre o sucesso educativo em dois colégios privados frequentados pelas classes dominantes. Porto: Afrontamento, 2014a. 
QUARESMA, Maria Luísa. A excelência no plural em colégios singulares. In: TORRES, Leonor Lima; PALHARES, José Augusto. Entre mais e melhor escola em democracia: inclusão e excelência no sistema educativo português. Lisboa: Mundos Sociais, 2014b. p. 117-132.

RAYOU, Patrick ; GLASMAN, Dominique. Les internats d'excellence: un nouveau défi éducatif? Lyon: Institut Français de l'Education, 2012.

RESENDE, José Manuel. Escolarização moderna: entre as promessas políticas e a tangibilidade da injustiça escolar. In: TORRES, Leonor Lima; PALHARES, José Augusto. Entre mais e melhor escola em democracia: inclusão e excelência no sistema educativo português. Lisboa: Mundos Sociais, 2014. p. 69-82.

TEDESCO, Juan Carlos. 0 novo pacto educativo: educação, competitividade e cidadania na sociedade moderna. Gaia: Fundação Manuel Leão, 2008.

TORRES, Leonor Lima. A ritualização da distinção acadêmica: 0 efeito cultura de escola. In: Entre mais e melhor escola em democracia: inclusão e excelência no sistema educativo português. Lisboa: Mundos Sociais, 2014. p. 27-47.

VAN AVERMAET, Piet; VAN HOUTTE, Mieke; VAN DEN BRANDEN, Kris. Promoting equity and excellence in education: an overview. In: VAN DEN BRANDEN, Kris, VAN AVERMAET, Piet; VAN HOUTTE, Mieke (Orgs.). Equity and excellence in education: towards maximal learning opportunities for all students. New York: Routledge, 2011.

VAN ZANTEN, Agnès. Un libéralisme éducatif sans frontières. In: VAN ZANTEN, Agnès (Org.). L'école l'état des savoirs. Paris: La Découverte, 2000. p. 355-364.

VIANA, Maria José Braga. 0 bom desempenho escolar nos meios populares: elementos para uma definição e alguns dados de pesquisa. Sociologia da Educação: Revista Luso-Brasileira, Rio de Janeiro, v. 2, n. 3, p. 7-24. mar. 2011.

VIEIRA, Maria Manuel. A fabricação da entrada em Medicina. Tensões, dilemas e suportes: In: TORRES, Leonor Lima; PALHARES, José Augusto. Entre mais e melhor escola em democracia: inclusão e excelência no sistema educativo português. Lisboa: Mundos Sociais, 2014. p. 49-67.

Recebido em: 15.10 .2014

Aprovado em: 11.03.2015

Maria Luísa Quaresma é professora e investigadora da Universidad Autónoma de Chile e investigadora associada do Instituto de Sociologia da Faculdade de Letras da Universidade do Porto. 